\title{
Democratic Provision of Divisible Public Goods
}

\author{
Hans Gersbach
}

CESIFo WORKING PAPER NO. 2939

CATEgory 1: Public FinAnCE

FEBRUARY 2010
An electronic version of the paper may be downloaded
- from the SSRN website:
- from the RePEc website:
- from the CESifo website:
www.SSRN.com
www.RePEc.org
www.CESifo-group.org/wp




\title{
Democratic Provision of Divisible Public Goods
}

\begin{abstract}
In this paper we examine the potential of democratic constitutions for the provision of divisible public goods in a large economy. Our main insights are as follows: When aggregate shocks are absent, the combination of the following rules yields first-best allocations: a supermajority rule, equal taxation, exemption of the agenda setter from taxation, and a ban on subsidies. In the presence of aggregate shocks to benefits or to costs of public-good provision, tax-sensitive majority rules, where the size of the required majority depends on the aggregate tax revenues, yield first-best allocations if a monotonicity condition is met. Finally, we explore the potential of first-best constitutions to induce voluntary participation by compensating agents belonging to the minority.
\end{abstract}

JEL-Code: D62, D72, H40.

Keywords: democratic constitutions, tax-sensitive majority rules, constitutional rules, provision of public goods.

\author{
Hans Gersbach \\ CER-ETH \\ Center of Economic Research at \\ ETH Zurich \\ Switzerland - 8092 Zurich \\ hgersbach@ethz.ch
}

First version: October 2008

This version: February 2010

I would like to thank Johannes Becker, Theresa Fahrenberger, Alia Gizatulina, and participants at the Workshop on Public Goods held at ETH Zurich in 2009 for valuable comments. 


\section{Introduction}

Democratic constitutions are a set of rules that must satisfy the liberal-democracy constraint, which consists of the following sub-constraints: every agent has the same chance of making a proposal; every individual has the right to vote; only yes/no votes are allowed at the voting stages; every individual is allowed to abstain from proposal-making. In this paper we examine whether and how democratic constitutions can achieve socially desirable outcomes when a polity chooses among a continuum of feasible levels for a public good. A democratic constitution that avoids under- or over-provision of public goods is called a first-best constitution.

The game

We consider public-good provision and public-good financing in a large-economy version of Hellwig (2005), embedded in a four-stage game. In the constitutional period, the society decides unanimously about the constitutional principles governing legislative decision-making. There is uncertainty regarding who will benefit how much from the public good. Moreover, there may be aggregate uncertainty regarding the benefits and costs of the public good. At the start of the legislative period, citizens observe the realization of aggregate benefits and costs as well as their own utility and decide simultaneously whether to apply for agenda-setting or not. Among all citizens who apply, one citizen is determined by fair randomization to set the agenda. The agenda-setter proposes a project-financing package. Citizens decide simultaneously whether to accept the proposal or not. This game is a direct translation of the four sub-constraints that constitute the liberal-democracy constraint. We explore the potential of a democratic constitution restricted to this kind of game. A democratic constitution is a set of rules specifying (i) how the agenda-setter is treated, (ii) which types of proposal are allowed, and (iii) how the society decides on a proposal.

Main results

The first insight of this paper is that the combination of the four following rules yields efficient provision of public goods when aggregate shocks are absent: (1) a supermajority rule under which the adoption of a particular level of a public good requires a prespecified vote-share; (2) a tax rule that levies the same tax rate on all individuals except the proposal-maker, who is exempted from taxation; (3) subsidies are forbidden; (4) the agenda-setter has to pay a fixed amount for agenda-setting. 
The second insight is that in the case of aggregate shocks to benefits and costs, the replacement of supermajority rules by tax-sensitive majority rules can preserve the efficiency of democratic constitutions. With a tax-sensitive majority rule, the majority required to put a proposal through is higher, the higher the aggregate tax revenues in a proposal are. As long as it holds that a higher amount of taxes in one state of the world is associated with a higher share of beneficiaries in comparison with the status quo, then appropriately designed tax-sensitive majority rules - in conjunction with the other constitutional rules - lead to first-best allocation.

The third insight of this paper is that it is always possible to find a democratic constitution that implements a Pareto-improvement over the status quo. There are also circumstances for which we can find first-best constitutions that fully compensate voting losers, so that the socially optimal level of the public good can be implemented as a Pareto-improvement.

In this novel constitution, two rules deserve particular attention. By making the required majority threshold a strictly monotonically increasing function of aggregate tax revenues, an agenda-setter cannot induce the adoption of an amount of the public good that is higher than socially desirable. The reason is that the required majority varies with the socially optimal amount of public goods, measured by the aggregate tax revenues in different states of the world. In addition, the required majority is set as equal to the share of individuals who strictly benefit from the proposal. By exempting the proposalmaker from taxation, while requiring equal tax treatment for all other individuals, the proposal-maker is forced to propose the highest possible level of the public good that would be adopted. This rule avoids under-provision of public goods.

\section{Motivation and relation to the literature}

My paper is a study in constructive constitutional economics, as outlined in the classic contribution by Buchanan \& Tullock (1962). Under a veil of ignorance, individuals decide which rules should govern legislative decision-making. In a long tradition dating back to Rousseau (1762), Buchanan \& Tullock (1962) have examined the costs and benefits of majority rules chosen by a society operating under a veil of ignorance.

Aghion \& Bolton (2003) have explicitly introduced contractual incompleteness for the design of optimal majority rules. They show how the simple or qualified majority rule can help to overcome ex-post vested interests. Gersbach (2009) has introduced the liberal-democracy constraint and explored democratic mechanisms for indivisible public 
goods. He has shown how increasingly sophisticated treatment and agenda rules, in conjunction with flexible or double majority rules, can yield first-best allocations for binary decisions.

We also use the liberal-democracy constraint to define the set of admissible mechanisms in this paper. In contrast to Gersbach (2009), however, we consider a model in which a society chooses among a continuum of possible public-good levels and we allow that benefits and costs may be affected by aggregate shocks during the legislative period. We introduce two novel rules which help to construct first-best allocations in such circumstances: aggregate-tax-sensitive majority rules and exemption of the proposal-maker from taxation. These rules, together with the other rules discussed in the introduction, avoid under- and over-provision of public good provision in circumstances with many different possible levels of public goods. Moreover, they induce that democratic public good provision adjusts optimally to fluctuations in costs and benefits of public goods.

The twin problem of societies - the risk of tyranny by the majority and the risk of legislation-blocking by the minority, as outlined in Aghion \& Bolton (2003) - has been further examined in Aghion, Alesina \& Trebbi (2004), who derive optimal supermajority governing rules that balance both of these dangers. Harstad (2005) develops a theory of majority rules based on the incentives of members of a club to invest in order to benefit from anticipated projects. Optimal majority rules balance two opposing forces. Large required majorities provide little incentive to invest because of hold-up problems, while the members of small majorities invest too much to become members of a majority coalition. We use aggregate-tax-sensitive majority rules to balance the power of majorities and minorities, in order to avoid under- or overprovision of public-good provision.

As a workhorse, we will use the large-economy model of Hellwig (2005). Our analysis is, however, more closely related to Hellwig (2003) who has examined public-good provision with many participants. In Section 5 we will discuss in detail how our results relate to Hellwig (2003).

The paper is organized as follows: In the next section we introduce the model and the constitutional rules we want to use. In section 3, we study first-best constitutions when aggregate uncertainty is absent. In section 4, we examine first-best constitutions when benefits or costs of public goods are subject to aggregate shocks. In section 5 , we explore the possibility of subsidizing voting losers to achieve voluntary participation. Section 6 concludes. 


\section{Model and Constitutional Rules}

\subsection{Model}

We consider a social-choice problem in public-good provision and financing in the largeeconomy model of Hellwig (2005). Time is indexed by $\tau=0,1$. The first period $\tau=0$ is the constitutional period, when a society of risk-neutral members decides how publicgood provision and financing should be governed in the legislative period $\tau=1$. The society consists of a continuum of voters represented by $[0,1]$.

In the legislative period $\tau=1$, each citizen is endowed with $y$ units of a private consumption good. Hence the society has an aggregate production capacity of $Y$, which can be used to provide an amount $C$ of aggregate consumption of a private commodity and a public good of level $Q$. The resource constraint amounts to

$$
C+K(Q)=Y
$$

The cost function $K(\cdot)$ is assumed to be strictly increasing, strictly convex, continuously differentiable, with $K(0)=0, K^{\prime}(0)=0$ and $\lim _{Q \rightarrow \infty} K^{\prime}(Q)=\infty$. Citizens are assumed to be risk-neutral.

A citizen derives utility $z Q$ from the level of public good $Q$. The parameter $z$ is the citizen's private information. From the perspective of the other citizens, or of the system as a whole, $z$ is the realization of a random variable that takes values in $[0,1]$ and has a probability distribution $F(\cdot)$ with mean $\bar{z}$ and density $f(\cdot)$. Applying a suitable version of the law of large numbers, $F(\cdot)$ can be interpreted as the distribution of $z$ in the population, and $\bar{z}$ is its mean. A citizen will be associated with his preference parameter $z$. As a shortcut, such a citizen is called citizen $z$.

The public good is financed by taxes, and citizens may be subsidized. We use $t(z)$ and $s(z)$ respectively to denote the tax payment or subsidy of a citizen with preference parameter $z$. Given a level $Q$ of public-good provision, the utility of citizen $z$ in the legislative period is given by

$$
U(z)=y+z Q-t(z)+s(z)
$$

Throughout the paper, we assume that $s(\cdot)$ and $t(\cdot)$ are integrable functions. We assume 
that $y$ is sufficiently large for the individuals to be able to pay the taxes proposed under any of the constitutions we will discuss. Finally, the budget constraint on the society in the legislative period is given by

$$
\int_{0}^{1} t(z) f(z) d z=K(Q)+\int_{0}^{1} s(z) f(z) d z .
$$

The aggregate tax revenue is denoted by $T$.

\subsection{Socially optimal solutions}

As citizens are risk-neutral, the optimal level of the public good, from an ex ante point of view, is the solution of the following problem:

$$
\max _{Q}\left\{\int_{0}^{1} z Q f(z) d z-K(Q)\right\} .
$$

Our assumptions imply that there exists a unique solution, denoted by $Q^{*}$, which is given by

$$
K^{\prime}\left(Q^{*}\right)=\bar{z}
$$

Hence, at the socially optimal level of the public good, the marginal cost of provision equals the expected marginal benefit. The first-best allocation does not determine the financing scheme and hence neither the taxes nor the subsidy functions. The sole constraint is the budget constraint. We also note that all individuals with $z \geq \bar{z}$ benefit from public-good provision if the costs are shared equally, i.e. $z Q^{*}>K\left(Q^{*}\right)$. To prove this fact, we observe that

$$
K^{\prime}(Q)>\frac{K(Q)}{Q}
$$

since $K(0)=0$ and $K^{\prime \prime}(Q)>0$. Hence, $\bar{z}=K^{\prime}\left(Q^{*}\right)>\frac{K\left(Q^{*}\right)}{Q^{*}}$, so individuals with $z \geq \bar{z}$ will strictly benefit from the provision of $Q^{*}$. 


\subsection{Democratic provision}

We use the liberal-democracy constraint, which requires that the legislative process operates under the following sub-constraints:

- Every agent has the same chance to make a proposal.

- Every individual has the right to vote.

- Only yes/no messages are allowed at the voting stages.

- Every individual is allowed to abstain from voting or applying for proposal-making. Several remarks are in order. First, Gersbach (2009), drawing on the philosophical foundations of democracy, provides an extensive justification of this constraint. Second, every citizen has the right to refrain from applying for agenda-setting. Once a citizen has applied and is selected, however, he may have to pay a cost, and thus becoming an agenda setter may be costly. The precise formalization of the liberal-democracy constraint is embodied in the game in the next subsection.

\subsection{The Game}

We consider the standard game that represents the sequence of constitutional and legislative periods:

Stage 0: In the constitutional period, the polity decides by the unanimity rule about the constitutional rules that govern the legislative processes.

Stage 1: At the start of the legislative period, citizens observe their preference parameter $z$. Citizens decide simultaneously whether to apply for agenda-setting $(\psi(z)=1$ or $\operatorname{not} \psi(z)=0)$.

Stage 2: Among all citizens who apply, one citizen is determined randomly to set the agenda. The preference parameter of the agenda-setter is denoted by $z_{a} \in[0,1]$. The agenda-setter proposes a project/financing package $(Q, t(\cdot), s(\cdot))$. Denote this choice by $P_{z_{a}}$.

Stage 3: Given $P_{z_{a}}$, citizens decide simultaneously whether to accept the proposal $\left(\delta_{z}\left(P_{z_{a}}\right)=1\right.$ or not $\left.\delta_{z}\left(P_{z_{a}}\right)=0\right)$. The polity decides about the proposal according to some majority rule specified in the constitution. 
The game fulfills the conditions constituting the liberal-democracy constraint. If nobody applies for agenda-setting, the status quo will prevail, which is characterized by $Q=0$, $t(\cdot)=s(\cdot)=0$. Hence the utility of a citizen in this case is $y$.

We use $\mathcal{P}=\left(P_{z}\right)_{z \in[0,1]: \psi(z)=1}$ to denote the set of possible proposals. The set of strategies can be summarized by

$$
\left\{\psi(z), \mathcal{P}, \delta_{z}(\cdot)\right\}_{z \in[0,1]}
$$

In deriving an equilibrium, we face the problem that as we have a continuum of voters an individual vote has no influence on the outcome. To describe the application and voting outcome in our model, we use the weak dominance criterion that mimics the optimal voting and application behavior of a society with a large but finite number of agents (see Gersbach (2005)). In our model, voting is a simple binary decision, so individuals have nothing to gain from strategic voting. Hence the above criterion implies that agents vote sincerely, i.e. agents will vote for their most-preferred alternative.

It is obvious that sincere voting on a proposal selects a unique voting equilibrium. Hence we can use the weak dominance criterion for the decision on whether to apply for agendasetting (stage 1). This concept is applied in the following way: We first look at the set of agents who can strictly improve their utility by making a proposal, compared to the status quo. In all of our constitutions, this set will be non-empty, and those agents will apply for agenda-setting. Moreover, in all of our constitutions an agenda-setter can never fare better if somebody other than himself makes a proposal. As a consequence, all individuals will apply for agenda-setting.

To simplify the exposition, we assume as a tie-breaking rule that, if an agent $z$ is indifferent between applying for agenda-setting and renouncing such an application, he will apply for agenda-setting, as we also assume that a citizen who is indifferent between voting yes or no will choose the former.

In what follows we always assume sincere voting and the above behavior regarding agenda-setting. We are now ready to characterize the expected level of the public good that a particular constitution can deliver. We say that a constitution $\mathcal{C}$ implements level $Q$ if all possible perfect Bayesian equilibria under constitution $\mathcal{C}$ that satisfy the above refinements and tie-breaking rules yield $Q$.

We call a constitution first-best if it implements the level $Q^{*}$. To prove that the constitutions we propose are first-best, we show that 
- all individuals apply for agenda-setting,

- each agenda-setter makes a proposal involving $Q^{*}$,

- this proposal will be adopted.

We finally note that in the constitutional period (stage 0 ), the society decides about the constitution by the unanimity rule. It is obvious that if a set of constitutional rules yields a first-best allocation, it will be approved unanimously in stage 0 , since individuals are identical at this point and risk-neutral.

\subsection{Constitutional principles}

The rules of the constitution have to specify

1. whether there is to be special treatment for the agenda-setter (agenda-setter rules);

2. restrictions on the agendas, i.e. definition of all constitutional agendas (agenda rules). An agenda consists of a project proposal and a financing package;

3. how the society decides on a proposal (decision rules).

We consider the following rules that will enable us to construct first-best constitutions.

\section{Agenda-setter rules}

- Costs of agenda-setting [CA(b)] The agenda-setter pays a fixed amount $b \geq 0$.

\section{Agenda rules}

- Equal taxation of citizens except the agenda-setter [ETT $\left.\boldsymbol{T}^{-z_{a}}\right]$ All citizens except the agenda-setter have to pay the same taxes.

- No subsidies [NS] The agenda-setter is not allowed to propose any subsidies.

- Budget constraint [BC]

The financing package must satisfy the budget constraint. 


\section{Decision rules}

- $m$-majority rule $[\boldsymbol{M}(\mathrm{m})]$

If a proposal to change the status quo receives at least a majority of $m$ percent of the citizens $(0 \leq m \leq 1)$, the proposal will be adopted.

- Tax-sensitive majority rule [F $\boldsymbol{M}(m(T))]$

Under a tax-sensitive majority rule, the required majority to support a proposal depends on aggregate taxes $T=\int_{0}^{1} t(z) d z$.

A priori we allow $m$ to be smaller than $\frac{1}{2}$. In section 3 we will discuss whether it is sensible to restrict $m$ to $m \geq \frac{1}{2}$. Note that the tax-sensitive majority rule may depend on information generated by the proposal. By contrast, the rules $[\mathrm{CA}(b)]$ and $[\mathrm{M}(m)]$ do not depend on the proposal but may depend on other parameters. We will call a proposal $P_{z_{a}}$ constitutional if the triple $\left(z_{a}, P_{z_{a}},\left\{\delta_{z}^{*}\left(P_{z_{a}}\right)\right\}_{z \in[0,1]}\right)$ does not violate the constitutional rules. $\left\{\delta_{z}^{*}\left(P_{z_{a}}\right)\right\}_{z \in[0,1]}$ denotes the equilibrium voting strategies of all individuals if $P_{z_{a}}$ is proposed.

Throughout the paper we assume that if a proposal violates the budget constraint, the status quo will prevail. If taxes exceed project costs and subsidies, we assume that excess revenues will be paid back uniformly to citizens, with the exception of the agenda-setter, as lump-sum transfer. As agenda-setters will never have an incentive to make a proposal with an unbalanced budget, we neglect this possibility in the following.

\section{First-Best Constitutions}

\subsection{The main theorem}

In this section we explore the structure of first-best constitutions. For the remainder of the paper we use $A V(Q)=\frac{K(Q)}{Q}$ to denote the average cost function.

We start with our first main result. We consider the following constitution

$$
\mathcal{C}_{1}:=\left\{[C A(\hat{b})],[N S],\left[E T T^{-z_{a}}\right],[M(\hat{m})]\right\},
$$


where

$$
\begin{aligned}
\hat{b} & =K\left(Q^{*}\right) \\
\hat{m} & =1-F\left(\frac{K\left(Q^{*}\right)}{Q^{*}}\right)=1-F\left(A V\left(Q^{*}\right)\right) .
\end{aligned}
$$

\section{Proposition 1}

Constitution $\mathcal{C}_{1}$ is first-best.

The proof of Proposition 1 is given in the Appendix.

The intuition for the result is as follows. We first stress that the cost $\hat{b}$ paid by the agenda setter is independent of the proposal. As the agenda setter is exempted from taxation, he is therefore interested in the maximal level of public goods that is adopted by the polity.

Consider next an individual $z$ with $z Q^{*}>K\left(Q^{*}\right)$. As observed in section 2.2, such individuals exist. For these individuals the proposal $\left(Q=Q^{*}, t^{-z_{a}}=K\left(Q^{*}\right)\right)$ is optimal, since this is the maximal level of the public good supported by at least $\hat{m}$ voters. An agenda-setter can avoid bearing taxes, but he has to pay $\hat{b}=K\left(Q^{*}\right)$. Hence individuals with $z Q^{*}>K\left(Q^{*}\right)$ are strictly better off with respect to the status quo if they can be the proposal-makers. Hence they apply for agenda-setting.

Consider an individual with $z Q^{*} \leq K\left(Q^{*}\right)$. If he can set the agenda, he can at most obtain $z Q^{*}-\hat{b}$. If he does not set the agenda, he will obtain $z Q^{*}-K\left(Q^{*}\right)=z Q^{*}-\hat{b}$. According to our tie-breaking rules, those individuals will apply for proposal-making and will propose $\left(Q=Q^{*}, t^{-z_{a}}=K\left(Q^{*}\right)\right)$. Accordingly, all individuals will apply for agenda-setting.

We stress that constitution $\mathcal{C}_{1}$ with any value of $\hat{b}$ in $\left[0, K\left(Q^{*}\right)\right]$ yields first-best allocations. A similar observation holds for all constitutions developed in this paper. In order to ensure that all agenda-setters will also contribute to the provision of public goods, we set $\hat{b}$ at the highest level that guarantees first-best allocations. ${ }^{1}$

A remark regarding the size of $\hat{m}$ is in order. A priori $\hat{m}$ can be smaller than $\frac{1}{2}$. As long as undertaking the public project is irreversible, $m<\frac{1}{2}$ is feasible. If, however, the

\footnotetext{
${ }^{1}$ This approach neutralizes the benefits from agenda-setting, and thus indirectly imposes equal burden sharing in this section. In a setting with a finite number of citizens, a particular level of agendasetting costs may be important to balance the budget.
} 
static process in this paper is repeated and the public good can be undone at little cost, $\hat{m}<\frac{1}{2}$ would invite cycling. In such cases it is sensible to restrict $\hat{m}$ to $\hat{m} \geq \frac{1}{2}{ }^{2}$

\subsection{An example}

Throughout the paper we will use a simple example to illustrate the results. We assume

$$
\begin{gathered}
K(Q)=a Q^{2} \\
f(z)= \begin{cases}1 & \text { if } z \in[0,1] \\
0 & \text { otherwise }\end{cases}
\end{gathered}
$$

Then, using $\bar{z}=\frac{1}{2}$ the first-best solution is given by

$$
Q^{*}=\frac{1}{4 a}
$$

Hence the set of parameters for the constitutional rules is given by

$$
\hat{b}=\frac{1}{16 a}, \hat{m}=1-\frac{a Q^{* 2}}{Q^{*}}=\frac{3}{4} .
$$

We note that a majority rule with a $75 \%$-vote threshold is needed to pass a proposal. An agenda-setter will propose $\left(Q^{*}=\frac{1}{4 a}, t^{-z_{a}}=\frac{1}{16 a}\right)$. For voter $\bar{z}=\frac{1}{2}$, benefits from public-good provision are $\bar{z} Q^{*}-K\left(Q^{*}\right)=\frac{1}{8 a}-\frac{1}{16 a}=\frac{1}{16 a}$.

\section{First-best Constitution and Aggregate Uncertainty}

In this section we explore which first-best constitutions exist when there is aggregate uncertainty regarding costs, benefits, or jointly regarded costs and benefits.

Different states of nature, e.g. different costs, imply different levels of socially desirable public good provision. Accordingly, the aggregate tax revenue may differ. In this case, we will use a tax-sensitive majority rule $[\boldsymbol{F} \boldsymbol{M}(m(T))]$ under which the required majority

\footnotetext{
${ }^{2}$ To ensure that such constitutions still yield first-best allocations, the tax rule has to be modified. A fraction of individuals does not pay taxes, while the remaining group of individuals shares the tax burden equally.
} 
depends on aggregate tax revenue. It will turn out that such rules can be constructed in a way that the majority requirement optimally adjusts to aggregate events.

To obtain first-best constitutions including this rule, we need the following monotonicity condition:

(MC): Suppose that socially optimal tax revenues associated with two different states of nature, say state 1 and state 2 satisfy $T^{1}>T^{2}$ then the shares of individuals benefiting from the provision of the socially optimal levels of public goods in both states satisfy $m^{1} \geq m^{2}$.

The (MC) states that a higher amount of taxes in one state of the world is associated with an equal or higher share of beneficiaries relative to the status quo. Note that in case of equal aggregate tax revenues, no conditions are imposed.

\subsection{Aggregate uncertainty regarding benefits}

In this section we consider the case of aggregate uncertainty regarding the benefits of the public good. In particular, we assume that a citizen derives utility $V=d z Q$ from the level of the public good. The random variable $z$ is the same as before, while $d$ is an aggregate shock. In particular, $d$ is either $d^{h}$ with probability $p(0 \leq p \leq 1)$ or $d^{l}$ $\left(d^{l}<d^{h}\right)$ with probability $1-p$.

We assume that the aggregate shock is realized after the constitution has been put in place, but before the legislative process starts. The socially optimal allocation is now characterized by two levels of public goods $\left(Q^{* h}, Q^{* l}\right)$ given by $d^{l} \bar{z}=K^{\prime}\left(Q^{* l}\right), d^{h} \bar{z}=$ $K^{\prime}\left(Q^{* h}\right)$, depending on whether $d^{h}$ or $d^{l}$ has been realized. We note that $Q^{* h}>Q^{* l}$ and hence $T^{h}=K\left(Q^{* h}\right)>T^{l}=K\left(Q^{* l}\right)$.

Moreover, we introduce

$$
\hat{m}^{X}=1-F\left(\frac{A V\left(Q^{* X}\right)}{d^{X}}\right) \text { for } X=h, l
$$

We note that $\hat{m}^{h}$ and $\hat{m}^{l}$ are equal to the shares of individuals who benefit from the proposal $\left(Q^{* h}, K\left(Q^{* h}\right)\right)$ and $\left(Q^{* l}, K\left(Q^{* l}\right)\right)$, where the states $h$ or $l$ occur respectively. 
Therefore the monotonicity condition (MC) requires that

$$
\hat{m}^{h} \geq \hat{m}^{l}
$$

has to hold. The condition states that the higher level of socially optimal tax revenue $T^{h}$ in the event of $d^{h}$ is associated with a higher share of citizens supporting the proposal $\left(Q=Q^{* h}, t^{-z_{a}}=K\left(Q^{* h}\right)\right)$ than the share of individuals supporting $\left(Q=Q^{* l}, t^{-z_{a}}=\right.$ $\left.K\left(Q^{* l}\right)\right)$ if $d^{l}$ occurs.

Hence (MC) is equivalent to

$$
\frac{d^{l}}{d^{h}} \leq \frac{A V\left(Q^{* l}\right)}{A V\left(Q^{* h}\right)}
$$

as

$$
\frac{d^{l}}{d^{h}}=\frac{K^{\prime}\left(Q^{* l}\right)}{K^{\prime}\left(Q^{* h}\right)}
$$

(MC) is equivalent to

$$
\frac{K^{\prime}\left(Q^{* l}\right)}{A V\left(Q^{* l}\right)} \leq \frac{K^{\prime}\left(Q^{* h}\right)}{A V\left(Q^{* h}\right)}
$$

and is thus ensured if $\mathrm{d} \ln K(Q) / \mathrm{d} \ln Q$ is weakly monotonically increasing.

We consider the following constitution:

$$
\mathcal{C}_{2}:=\left\{[C A(\hat{b})],[N S],\left[E T T^{-z_{a}}\right],\left[F M\left(m^{*}(T)\right)\right]\right\}
$$

where

$$
\begin{aligned}
\hat{b} & =K\left(Q^{* l}\right) \\
m^{*}(T) & = \begin{cases}\hat{m}^{h} & \text { if } T>T^{l} \\
\hat{m}^{l} & \text { otherwise }\end{cases}
\end{aligned}
$$

The following proposition shows that $\mathcal{C}_{2}$ can yield first-best allocations independently of whether $d^{h}$ or $d^{l}$ occurs.

\section{Proposition 2}

Suppose $(M C)$ holds. Then constitution $\mathcal{C}_{2}$ is first-best.

The proof of Proposition 2 is given in the Appendix. The intuition for the result runs as follows: Suppose that $d^{l}$ is realized. Any agenda-setter will propose $\left(Q^{* l}, t^{-z_{a}}=K\left(Q^{* l}\right)\right)$, which will be supported by a share of $\hat{m}^{l}$ voters. Since $m^{*}\left(T^{l}\right)=\hat{m}^{l}$, the proposal 
is adopted. A higher amount of the public good will gain less than $\hat{m}$ voters and thus will not be adopted, as $\hat{m}^{h} \geq \hat{m}^{l}$. Suppose that $d^{h}$ is realized. The proposal $\left(Q^{* h}, t^{-z_{a}}=K\left(Q^{* h}\right)\right)$ will be made by an agenda-setter, as it gains just $\hat{m}^{h}$ voters.

We observe that the scheme $m^{*}(T)$ has a built-in flexibility, as the majority threshold depends on the aggregate tax outlays. In equilibrium, these tax revenues will vary according to whether $d^{h}$ or $d^{l}$ occurs. This feedback from aggregate tax revenues to the majority threshold means that the first-best allocations can be produced in both states.

We note that we can generalize the result to more complicated discrete or continuous distributions of $d$ as long as (MC) holds. If (MC) holds, the ensuing function $m^{*}(T)$ is monotonically increasing and thus we can apply the construction in Proposition 2.

We illustrate Proposition 2 with the same example we introduced in the last section. We assume, in addition, that $d^{l}=\frac{1}{2}$ and $d^{h}=\frac{3}{2}$. The socially optimal levels of the public good are $Q^{* l}=\frac{1}{8 a}, Q^{* h}=\frac{3}{8 a}$. Hence $T^{l}=\frac{1}{64 a}, T^{h}=\frac{9}{64 a}$.

$$
\begin{aligned}
& \hat{m}^{h}=1-F\left(\frac{\frac{9}{64 a}}{\frac{3}{8 a} \cdot \frac{3}{2}}\right)=1-F\left(\frac{1}{4}\right)=\frac{3}{4}, \\
& \hat{m}^{l}=1-F\left(\frac{\frac{1}{64 a}}{\frac{1}{8 a} \cdot \frac{1}{2}}\right)=1-F\left(\frac{1}{4}\right)=\frac{3}{4} .
\end{aligned}
$$

Hence $(\mathrm{MC})$ holds, and constitution $\mathcal{C}_{2}$ yields a socially efficient outcome.

\subsection{Aggregate uncertainty regarding costs}

We next consider the opposite case, aggregate uncertainty regarding the costs of public goods. In particular, we assume that the cost of providing the public good is $\omega K(Q)$. The random variable represents the aggregate shock: $\omega$ can be either $\omega^{h}$ with probability $p$, or $\omega^{l}$ with probability $1-p$, where $\omega^{h}>\omega^{l}$. Again, the aggregate shock is realized at the beginning of the legislative process.

The socially optimal allocation is characterized by two levels of public goods, $Q^{* h}, Q^{* l}$, defined by $\bar{z}=\omega^{h} K^{\prime}\left(Q^{* h}\right), \bar{z}=\omega^{l} K^{\prime}\left(Q^{* l}\right)$. We note that $Q^{* h}<Q^{* l}$. 
As in the case of aggregated uncertainty regarding benefits, for $X=h, l$ we define

$$
T^{X}=\omega^{X} K\left(Q^{* X}\right), \quad \hat{m}^{X}=1-F\left(\frac{\omega^{X} K\left(Q^{* X}\right)}{Q^{* X}}\right)
$$

The monotonicity condition (MC) is fulfilled if and only if neither

$$
T^{h}>T^{l} \text { and } m^{l}>m^{h}
$$

nor

$$
T^{l}>T^{h} \text { and } m^{h}>m^{l},
$$

so the requirement is that the tax levels and the corresponding fractions of supporting individuals be "co-monotonic." We note that (MC) is always fulfilled for cost functions $K(Q)=a Q^{n}$ with $n \in \mathbb{N}, n>1$, since in this case

$$
Q^{* X}=\left(\frac{\bar{z}}{\omega^{X} a n}\right)^{1 /(n-1)}
$$

and therefore

$$
m^{X}=1-F\left(\frac{\omega K\left(Q^{* X}\right)}{Q^{* X}}\right)=1-F(\bar{z} / n)
$$

is independent of $\omega^{X}$.

We consider the following constitution:

$$
\mathcal{C}_{3}:=\left\{[C A(\hat{b})],[N S],\left[E T T^{-z_{a}}\right],\left[F M\left(m^{*}(T)\right)\right]\right\}
$$

where

$$
\hat{b}=\min \left\{T^{l}, T^{h}\right\}
$$

and

$$
m^{*}(T)= \begin{cases}\max \left\{\hat{m}^{h}, \hat{m}^{l}\right\} & \text { if } T>\min \left\{T^{h}, T^{l}\right\} \\ \min \left\{\hat{m}^{h}, \hat{m}^{l}\right\} & \text { otherwise. }\end{cases}
$$

We obtain

\section{Proposition 3}

Suppose (MC) holds. Then constitution $\mathcal{C}_{3}$ is first-best. 
The proof of Proposition 3 is given in the Appendix. The intuition is similar to the case where there is aggregate uncertainty regarding benefits. The majority rule is a step function, and in equilibrium the required majority threshold becomes contingent on the aggregate state. This yields socially efficient allocations.

For our parametrized example we choose $\omega^{h}=\frac{3}{2}$ and $\omega^{l}=\frac{1}{2}$. The socially optimal amounts of public goods are $Q^{* h}=\frac{1}{6 a}$ and $Q^{* l}=\frac{1}{2 a}$, therefore $T^{h}=\frac{1}{2 a}$ and $T^{l}=\frac{1}{8 a}$,

$$
\begin{aligned}
& \hat{m}^{h}=1-F\left(\frac{\frac{1}{36 a}}{\frac{1}{6 a} \cdot \frac{2}{3}}\right)=1-F\left(\frac{1}{4}\right)=\frac{3}{4}, \\
& \hat{m}^{l}=1-F\left(\frac{\frac{1}{4 a}}{\frac{1}{2 a} \cdot \frac{2}{1}}\right)=1-F\left(\frac{1}{4}\right)=\frac{3}{4} .
\end{aligned}
$$

We now give a second example, this time with $T^{h}=T^{l}$, so that the monotonicity condition is trivially satisfied. Suppose that $K(Q)=e^{2 Q}$ and $F(z)=z$ for all $z \in[0,1]$, i.e. $z$ is uniformly distributed on $[0,1]$. As before, $\omega^{l}=\frac{1}{2}$ and $\omega^{h}=\frac{3}{2}$. Then, using $\bar{z}=\frac{1}{2}$, the first-best solutions are given by

$$
Q^{* h}=\frac{1}{2} \log \left(\frac{1}{4 \omega^{h}}\right) \text { and } Q^{* l}=\frac{1}{2} \log \left(\frac{1}{4 \omega^{l}}\right) .
$$

Hence $Q^{* l}>Q^{* h}$. Aggregate tax revenue is given by

$$
T^{h}=\omega^{h} e^{\frac{2}{2} \log \left(\frac{1}{4 \omega^{h}}\right)}=\frac{1}{4}=T^{l}=\omega^{l} e^{\frac{2}{2} \log \left(\frac{1}{4 \omega^{l}}\right)} .
$$

In this case, the corresponding majorities differ:

$$
\hat{m}^{h}=1-F\left(\frac{T^{h}}{Q^{* h}}\right)=1-\frac{\bar{T}}{Q^{* h}}<\hat{m}^{l}=1-\frac{\bar{T}}{Q^{* l}} \quad \text { where } \bar{T}:=T^{h}=T^{l}
$$

as $Q^{* l}>Q^{* h}$. According to Proposition 3, constitution $\mathcal{C}_{3}$ is first-best. 


\subsection{Joint aggregate uncertainty}

In this section we consider the most demanding case, joint aggregate uncertainty regarding benefits and costs.

In particular, we assume that the citizens' utility is $d z Q$ with $d$ being $d^{h}$ or $d^{l}, d^{h}>d^{l}$, while the aggregate cost of providing the amount $Q$ is $\omega K(Q)$ with $\omega$ being $\omega^{h}$ or $\omega^{l}$, $\omega^{h}>\omega^{l}$. The possible states of the world are

$$
\left(d^{h}, \omega^{h}\right),\left(d^{h}, \omega^{l}\right),\left(d^{l}, \omega^{h}\right),\left(d^{l}, \omega^{l}\right) .
$$

The socially optimal allocation is characterized by $d^{i} \bar{z}=\omega^{j} K^{\prime}\left(Q^{* i j}\right), i, j \in\{l, h\}$.

We obtain

$$
Q^{* h l}>\max \left\{Q^{* h h}, Q^{* l l}\right\}>\min \left\{Q^{* h h}, Q^{* l l}\right\}>Q^{* l h} .
$$

Moreover, $Q^{* h h}>Q^{* l l}$ if and only if $\frac{d^{h}}{\omega^{h}}>\frac{d^{l}}{\omega^{l}}$. We define the corresponding levels of aggregate taxes as

$$
T^{i j}=\omega^{j} K\left(Q^{* i j}\right), i, j \in\{l, h\} .
$$

The first index $i$ of $T^{i j}$ denotes the level of benefits, the second index $j$ denotes the level of costs. It is not possible in general to determine how $T^{i j}$ relates to all other $T^{l k}$ for $i, j, k, l \in\{h, l\}$. For example, it is obvious that $T^{h l}=\omega^{l} K\left(Q^{* h l}\right)>\omega^{l} K\left(Q^{* l l}\right)=T^{l l}$, as $Q^{* h l}>Q^{* l l}$, but without further assumptions we cannot say whether $T^{h l}=\omega^{l} K\left(Q^{* h l}\right)>$ $\omega^{h} K\left(Q^{* h h}\right)=T^{h h}$ holds, although $Q^{* h l}>Q^{* h h}$ is true as well.

We define

$$
\hat{m}^{i j}=1-F\left(\frac{\omega^{j} K\left(Q^{* i j}\right)}{d^{i} Q^{* i j}}\right) .
$$

The monotonicity condition implies that no two states $X, Y \in\{(h, h),(h, l),(l, h),(l, l)\}$ exist such that $T^{X}>T^{Y}$ and $m^{Y}>m^{X}$. Thus the monotonicity condition implies that the states of the world can be named $A, B, C, D$ such that

$$
T^{A} \geq T^{B} \geq T^{C} \geq T^{D} \text { and } m^{A} \geq m^{B} \geq m^{C} \geq m^{D} .
$$

We consider the following constitution:

$$
\mathcal{C}_{4}:=\left\{[C A(\hat{b})],[N S],\left[E T T^{-z_{a}}\right],\left[F M\left(m^{*}(T)\right)\right]\right\}
$$


where $\hat{b}=T^{D}$ and

$$
m^{*}(T)= \begin{cases}m^{D} & \text { if } T \leq T^{D}, \\ m^{C} & \text { if } T^{D}<T \leq T^{C}, \\ m^{B} & \text { if } T^{C}<T \leq T^{B}, \\ m^{A} & \text { if } T^{B}<T .\end{cases}
$$

The monotonicity condition ensures that with this constitution a fraction of at least $m^{X}$ of supporting voters is needed to bring through a proposal that involves a tax level strictly higher than $T^{X}$. We point out that this statement holds true, even if one of the cases in the definition of $m^{*}$ collapses to the empty set. Assume, for example, the parameters are such that $T^{C}=T^{B}$. Then, to bring through a proposal involving a tax level strictly higher that $T^{B}$, one would need a fraction of at least $m^{A} \geq m^{B}$ supporting voters.

This characteristic of the constitution is the key to the following Proposition:

\section{Proposition 4}

Suppose $(M C)$ holds. Then constitution $\mathcal{C}_{4}$ is first-best.

The proof of Proposition 4 is given in the Appendix.

\section{Example 1}

For the example introduced in section 3.2, i.e. $K(Q)=a Q^{2}$ and $F(x)=x$, we may choose $\omega^{l}=\frac{1}{2}, \omega^{h}=\frac{3}{2}, d^{h}=\frac{3}{2}$ and $d^{l}=\frac{1}{2}$. The socially optimal levels of the public good are $Q^{* h h}=\frac{1}{4 a}=Q^{* l l}, Q^{* h l}=\frac{3}{4 a}$ and $Q^{* l h}=\frac{1}{12 a}$. It follows that $T^{h h}=\frac{3}{32 a}, T^{l l}=$ $\frac{1}{32 a}, T^{h l}=\frac{9}{32 a}$ and $T^{l h}=\frac{3}{288 a}$. We obtain the following ordering:

$$
T^{h l}>T^{h h}>T^{l l}>T^{l h} .
$$

The required majorities are again given by

$$
\hat{m}^{h l}=\hat{m}^{h h}=\hat{m}^{l l}=\hat{m}^{l h}=\frac{3}{4} .
$$

Hence constitution $\mathcal{C}_{4}$ is first-best. 


\section{Example 2}

As a second example, take the same set-up as in example 1 , but use $K(Q)=e^{\frac{1}{8} Q}-1$ instead of $K(Q)=a Q^{2}$. As $K^{\prime}(Q)=\frac{1}{8} e^{\frac{1}{8} Q}$ we obtain $Q^{* i j}=8 \log \left(\frac{4 d^{i}}{\omega^{j}}\right)$. Separately for each possible state, the socially optimal levels of public good are given by

$$
Q^{* h h}=Q^{* l l}=8 \log (4) \approx 11.1, Q^{* h l}=8 \log (12) \approx 19.9 \text { and } Q^{* l h}=8 \log \left(\frac{4}{3}\right) \approx 2.3,
$$

i.e. we have $Q^{* h l}>Q^{* h h}=Q^{* l l}>Q^{* l h}$. The general form of the corresponding tax level is $T^{i j}=\omega^{j} K\left(Q^{* i j}\right)=4 d^{i}-\omega^{j}$. Hence we obtain

$$
T^{h h}=\frac{9}{2}, T^{l l}=\frac{3}{2}, T^{h l}=\frac{11}{2}, T^{l h}=\frac{1}{2},
$$

so $T^{h l}>T^{h h}>T^{l l}>T^{l h}$. Finally, the associated $m^{i j}=1-\frac{T^{i j}}{d^{i} Q^{* i j}}$ are given by

$$
m^{h h}=m^{l l} \approx 0.73, m^{h l} \approx 0.82 \text { and } m^{l h} \approx 0.57
$$

The ordering is given by $m^{h l}>m^{h h}=m^{l l}>m^{l h}$. Again constitution $\mathcal{C}_{4}$ implements a first-best allocation.

\section{Ex Post Constraints}

Common to all our constitutions is the property that individuals with low valuations of the public good are worse off with democratic provision of public goods than with the status quo. In principle, as democratic constitutions are chosen by unanimity under a veil of ignorance, ex post constraints do not need to be honored, as the constitution legitimizes the government's power to tax people.

In this section, we nevertheless explore whether ex post constraints could be honored. The reason is threefold. First, individuals may leave ex post the jurisdiction if they suffer too much. Second, as in Hellwig (2005), citizens may opt for social welfare functions with inequality aversion. Third, honoring ex post constraints allows us to relate the constitutions to the standard mechanism literature.

In particular, we explore in this section the scope of subsidizing voting losers without sacrificing the efficiency properties of the constitution. In particular, we assume that all individuals who voted against the proposal will receive a subsidy $s^{L}>0$. We denote 
that by the rule $S L\left(s^{L}\right)$. In a continuum model, such a rule would destroy the efficiency properties of our constitutions, as knowing that they have no impact on the voting outcome, individuals would oppose any proposal in order to receive $s^{L}$. In a finite version of our economy this is less clear, as individuals may be pivotal. To explore the potential of our constitutions under such circumstances, we keep the tractable structure of our continuum framework, but we assume the

No-switching assumption: All individuals in a subset $\Omega \subseteq[0,1]$ will support a proposal $P$ if the following conditions are met:

(i) All individuals $i \in \Omega$ are better off with $P$ than with the status quo. All $i \in[0 ; 1] \backslash \Omega$ are worse off with the proposal than without.

(ii) Proposal $P$ is adopted if it is seconded by all agents in $\Omega$.

(iii) Proposal $P$ is rejected if a subset of $\Omega$ with positive measure votes $P$ down.

The no-switching assumption mimics being pivotal in a finite population. It is the best possible assumption for constitutions to work in the continuum version of our model. ${ }^{3}$ Our main result in this section shows that, with this assumption, participation may be eased and general voluntary participation and first-best allocation may be compatible. We use the model variant with no aggregate risk.

\section{Proposition 5}

(i) There exists an $s^{L}>0$ and an $\hat{m}$ such that the constitution

$$
\tilde{\mathcal{C}}_{1}=\left\{[C A(\hat{b})],\left[S L\left(s^{L}\right)\right],\left[E T T^{-z_{a}}\right],[M(\hat{m}]\}\right.
$$

with

$$
\hat{b}=0
$$

yields a positive level of $Q$. The resulting allocation is a Pareto-improvement over the status quo.

(ii) There are constellations (e.g. $f(z)=1, K(Q)=a Q^{2}$ ), an $s^{L}>0$ and $\hat{m}$, such that $\tilde{C}_{1}$ yields $Q^{*}$ and the allocation is a Pareto-improvement over the status quo.

(iii) There are constellations for which there exists no $s^{L}>0$ and $\hat{m}$, such that $\tilde{C}_{1}$ yields $Q^{*}$ and no individual is worse off compared to the status quo.

\footnotetext{
${ }^{3}$ To ensure no-switching in a continuum model, one would need open ballots and coordination of voting behavior, such that switching by one individual $i \in \Omega$ would simultaneously trigger deviation by a subset in $\Omega$ of positive measure.
} 
The proof is given in the Appendix. Proposition 5 shows that, under the favorable no-swithing assumption, democratic constitutions can engineer a Pareto-improvement. When $z$ is uniformly distributed it is even possible for democratic constitutions to simultaneously yield first-best levels of $Q$ and voluntary participation.

When we allow voluntary participation, we address the same question as Hellwig (2003), albeit with an infinite number of agents. It is thus important to relate the above Proposition to his results.

We first observe that the impossibility result of Hellwig (Proposition 3.10), according to which incentive-compatibility obviates the implementation of first-best outcomes, does not apply in our framework, as Hellwig's argument is based on the agents' uncertainty about the amount of the public good that will be provided. This uncertainty, in turn, results from the agents' uncertainty about the actual distribution of types in the society. The uncertainty vanishes if - as is the case in our model - the number of agents tends to infinity. In the limit, the implementation of first-best outcomes may be possible, as is shown by the example given above in Proposition 5, part (ii).

Second, Proposition 6.1 of Hellwig's paper states that when the number of agents becomes large, the quantity of the public good provided under a second-best, incentivecompatible mechanism follows approximately a (truncated) normal distribution around the first-best quantity. The variance is proportional to $n$ when the utility is linear and costs are quadratic. For our model - in which the set of agents is normalized to the unit interval - to be obtained as a limit of a model with finitely many agents, quantities must be rescaled with $1 / n$, which gives a variance proportional to $1 / n$. In the limit, the variance vanishes, and the mechanism implements the first-best outcome. Our example is thus also in line with Hellwig's result in Proposition 6.1.

\section{Conclusion}

Our analysis has shed light on the potential of liberal democracies for achieving firstbest allocations. Numerous issues deserve further attention in this research program. Most importantly, it will be useful to investigate optimal constitutions for circumstances where the monotonicity condition is violated. 


\section{Appendix: Proofs}

\section{Proof of Proposition 1}

Step 1: We first consider individuals for which $z Q^{*}>K\left(Q^{*}\right)$. Such individuals always exist, as set out in section 2.2. Suppose that such an individual applies for agendasetting and is recognized. We claim that he will propose $\left(Q=Q^{*}, t^{-z_{a}}=K\left(Q^{*}\right)\right)$. For notational convenience, as all proposals will involve $s(\cdot) \equiv 0$, the subsidy function is neglected in the following.

This proposal will be accepted, as a share of $\hat{m}=1-F\left(A V\left(Q^{*}\right)\right)$ voters are better off than with the status quo and will thus support the proposal. The utility of the agendasetter is $z Q^{*}-\hat{b}=z Q^{*}-K\left(Q^{*}\right)>0$. A proposal $\left(Q<Q^{*}, t^{-z_{a}}=K(Q)\right)$ would also be accepted but generates smaller utility $z Q-\hat{b}=z Q-K\left(Q^{*}\right)$ for the agenda-setter. A proposal $\left(Q>Q^{*}, t^{-z_{a}}=K(Q)\right)$ would not be adopted as the share of supporting voters is smaller than $\hat{m}$. Hence individuals with $z Q^{*}>K\left(Q^{*}\right)$ strictly benefit from setting the agenda, relative to the status quo, and will thus apply for agenda-setting and make a proposal $\left(Q=Q^{*}, t^{-z_{a}}=K\left(Q^{*}\right)\right)$ if recognized.

Step 2: Consider an individual with $z Q^{*} \leq K\left(Q^{*}\right)$. Suppose that he applies for agendasetting and is chosen to make a proposal. As he has to pay $\hat{b}=K\left(Q^{*}\right)$ and can renounce taxing himself, the same considerations as in Step 1 imply that the best proposal is $(Q=$ $\left.Q^{*}, t^{-z_{a}}=K\left(Q^{*}\right)\right)$. According to our tie-breaking rule, all individuals with $z Q^{*} \leq K\left(Q^{*}\right)$ apply for agenda-setting, as they are indifferent between applying and not applying.

\section{Proof of Proposition 2}

Step 1: Suppose that $d^{l}$ has been realized. As the costs for an agenda-setter are fixed, a citizen who applies for agenda-setting and who is recognized as such proposes the maximum level of public goods that will be supported by the electorate. The candidate proposal $\left(Q^{* l}, t^{-z_{a}}=K\left(Q^{* l}\right)\right)$ is supported by a share of $\hat{m}^{l}$ voters, and the proposal will be accepted, since $T \leq T^{l}$ and the vote threshold $\hat{m}^{l}$ applies.

Any proposal $\left(Q, t^{-z_{a}}=K(Q)\right)$ with $Q>Q^{* l}$ would be rejected, as fewer than $\hat{m}^{l}$ voters will support the proposal and $\hat{m}^{h} \geq \hat{m}^{l}$ supporting votes would be required. Hence the candidate proposal is optimal.

Following the same logic as in Proposition 1, all citizens will apply for agenda-setting. 
Step 2: Suppose that $d^{h}$ has been realized. Any agenda-setter will propose $\left(Q^{* h}, t^{-z_{a}}=\right.$ $\left.K\left(Q^{* h}\right)\right)$ in this case.

The proposal would be supported by $\hat{m}^{h}$ voters. As $T>T^{l}$, the required threshold is also $\hat{m}^{h}$, so the proposal is adopted. A higher level of public goods would be supported by a fraction of voters less than $\hat{m}^{h}$.

By the same logic as in Proposition 1, all citizens will apply for agenda-setting.

\section{Proof of Proposition 3}

The monotonicity condition implies that the two possible states of the world, $h$ and $l$, can be renamed $A$ and $B$, i. e. $\{A, B\}=\{h, l\}$, such that both $T^{A} \geq T^{B}$ and $m^{A} \geq m^{B}$. Now

$$
m^{*}(T)= \begin{cases}\hat{m}^{A} & \text { for } T>T^{B} \\ \hat{m}^{B} & \text { for } T \leq T^{B} .\end{cases}
$$

Step 1: Suppose that $\omega^{B}$ has been realized. Suppose that an individual is recognized as the agenda-setter. By the same line of reasoning as in Proposition 2, he proposes $\left(Q^{* B}, t^{-z_{a}}=\omega^{B} K\left(Q^{* B}\right)\right)$, which is supported by a share of $\hat{m}^{B}$ voters and accepted, since $T \leq T^{B}$ and the vote threshold $\hat{m}^{B}$ applies. Any proposal $\left(Q, t^{-z_{a}}=\omega^{B} K(Q)\right)$ with $Q>Q^{* B}$ would be rejected, as strictly fewer than $\hat{m}^{B}$ voters would support the proposal and $\hat{m}^{A} \geq \hat{m}^{B}$ supporting voters would be required. Following the same logic as in Proposition 1, all citizens will apply for agenda-setting.

Step 2: Suppose that $\omega^{A}$ has been realized. Again, using the same logic, an agendasetter will propose $\left(Q^{* A}, t^{-z_{a}}=\omega^{A} K\left(Q^{* A}\right)\right)$, which will be adopted as it is supported by $\hat{m}^{A}$ voters. A strictly higher level of the public good would not be adopted, as it would be supported by a strictly smaller measure of voters than $\hat{m}^{A}$, while the required threshold would be $\hat{m}^{A}$ since the corresponding tax-level would be strictly higher than $T^{A} \geq T^{B}$. Again, all citizens apply for agenda-setting.

\section{Proof of Proposition 4}

Suppose that state $X \in\{A, B, C, D\}$ has been realized, associated with the event $\left(d^{i}, \omega^{j}\right), i, j \in\{l, h\}$. Suppose that an individual is recognized as the agenda-setter. We claim that he will propose $\left(Q=Q^{X}, t^{-z_{a}}=\omega^{j} K\left(Q^{X}\right)=T^{X}\right)$.

The candidate proposal is supported by a share of $\hat{m}^{X}$ voters. The proposal will be accepted, since $T \leq T^{X}$ and a vote threshold of at most $\hat{m}^{X}$ applies. Any proposal 
$\left(Q, t^{-z_{a}}=\omega^{j} K(Q)\right)$ with $Q>Q^{X}$ would be rejected, since strictly fewer than $\hat{m}^{X}$ voters would support the proposal, but, as we have already pointed out above, just before Proposition 4, at least $\hat{m}^{X}$ supporting voters would be required. Every agenda-setter proposes the maximum level of public goods that will be supported by the electorate. Any proposal $\left(Q, t^{-z_{a}}=\omega^{j} K(Q)\right)$ with $Q<Q^{X}$ will not maximize the utility of the agenda-setter, hence such a proposal will not be made. The candidate proposal is, therefore, optimal.

Following the same logic as in Proposition 1, all citizens will apply for agenda-setting.

\section{Proof of Proposition 5}

Step 1: We construct a Pareto-improvement. Making a proposal with $Q>0$ that is a Pareto-improvement over the status quo requires that

$$
s^{L}=t
$$

since there is an individual with $z=0$ and thus individuals rejecting the proposal need to be compensated for their taxes.

Step 2: Suppose that a level $Q>0$ is proposed. The budget constraint is

$$
t=K(Q)+t \cdot F\left(\frac{t}{Q}\right)
$$

which implicitly determines the tax rate $t$. A share of $F(t / Q)$ individuals have to be subsidized by $s^{L}=t$. Costs to provide the public good and subsidies have to be covered by taxes.

Step 3: We prove point (i). Let us choose $\kappa$ such that $F(\kappa)=\frac{1}{2}$. Let us choose $\hat{Q}$ to be arbitrarily small. Hence $K^{\prime \prime}(\hat{Q}) \hat{Q}<\frac{1}{2} \kappa$. For $t=\kappa \hat{Q}$, the left-hand side of equation (3) is larger than the right-hand side, as

$$
K^{\prime \prime}(\hat{Q}) \hat{Q}^{2}+\mathrm{O}\left(\hat{Q}^{3}\right)+\frac{1}{2} \kappa \hat{Q}<\kappa \hat{Q}+\mathrm{O}\left(\hat{Q}^{3}\right)
$$

For $t=0$, the right-hand side is larger than the left-hand side. Hence, by the Intermediate Value Theorem, there exists $\hat{t}$ such that

$$
\hat{t}=K(\hat{Q})+\hat{t} F\left(\frac{\hat{t}}{\hat{Q}}\right)
$$


with $\hat{t}<\kappa \hat{Q}$ and $F(\hat{t} / \hat{Q})<\frac{1}{2}$.

Hence, if we set

$$
\hat{m}=1-F\left(\frac{\hat{t}}{\hat{Q}}\right)>\frac{1}{2}
$$

and invoke the no-switching assumption, constitution $\tilde{\mathcal{C}}_{1}$ will implement $\hat{Q}$. This is a Pareto-improvement, as a fraction $\hat{m}$ of individuals is better off with the public good and paying $\hat{t}$, and a fraction $1-\hat{m}$ is better off with the public good, as they receive subsidies $s^{L}=\hat{t}$. Only an individual with $z=0$ is indifferent between the status quo and providing $\hat{Q}$

Step 4: We prove point (ii) and (iii) by examples. First, the budget constraint can be rewritten as

$$
\left(1-F\left(t / Q^{*}\right)\right) t=K\left(Q^{*}\right)
$$

Example A: Let us assume that $z$ is uniformly distributed and $K(Q)=\frac{1}{2} Q^{2}$. Then

$$
Q^{*}=\frac{1}{2}
$$

The budget constraint is

$$
(1-2 t) t=\frac{1}{8}
$$

This equation has a unique solution at $t^{*}=\frac{1}{4}$. We set $\hat{m}=\frac{1}{2}$. At a tax rate $t^{*}=\frac{1}{4}$ all citizens with $z>\frac{1}{2}$ have a utility $z Q^{*}-t^{*}>0$. All individuals with $z<\frac{1}{2}$ would be worse off without subsidization. With subsidies their utility is $z Q^{*}$. Example A proves (ii).

Example B: Again let $K(Q)=\frac{1}{2} Q^{2}$ and let $f(z)=2-2 z$, which yields $F(z)=2 z-z^{2}$. The mean value is given by $\bar{z}=\int_{0}^{1}\left(2 z-2 z^{2}\right) d z=\frac{1}{3}$. Hence $Q^{*}=\frac{1}{3}$. The budget constraint becomes

$$
\left(1-6 t+9 t^{2}\right) t=\frac{1}{18}
$$

which has no solution in the interval $\left[0 ; Q^{*}\right]$. This example proves (iii). 


\section{References}

Aghion, P., A. Alesina, and F. Trebbi (2004), "Endogenous Political Institutions", Journal of Political Economy, 119, 565-612.

Aghion, P., and P. Bolton (2003), "Incomplete Social Contracts", Journal of the European Economic Association, 1, 38-67.

Buchanan, J. M., and G. Tullock (1962), The Calculus of Consent: Logical Foundations of Constitutional Democracy, University of Michigan Press.

Gersbach, H. (2005), Designing Democracy: Ideas for Better Rules, Heidelberg, Springer.

Gersbach, H. (2009), "Democratic Mechanisms", Journal of the European Economic Association.

Harstad, B. (2005), "Majority Rules and Incentives", Quarterly Journal of Economics, 120, 1535-1568.

Hellwig, M. (2003), "Public-Good Provision with Many Participants", Review of Economic Studies, 70, 589-614.

Hellwig, M. (2005), "A Utilitarian Approach to the Provision and Pricing of Excludable Public Goods," Journal of Public Economics, 89, 1981-2003.

Rousseau, J.-J. (1762), Du contrat social ou principes du droit politique, Marc-Michel Rey, Amsterdam, translated by Maurice Cranston (1968) as The Social Contract, Penguin Classics, London. 


\section{CESifo Working Paper Series}

for full list see www.cesifo-group.org/wp

(address: Poschingerstr. 5, 81679 Munich, Germany, office@cesifo.de)

2877 Martin Schlotter, Guido Schwerdt and Ludger Woessmann, Econometric Methods for Causal Evaluation of Education Policies and Practices: A Non-Technical Guide, December 2009

2878 Mathias Dolls, Clemens Fuest and Andreas Peichl, Automatic Stabilizers and Economic Crisis: US vs. Europe, December 2009

2879 Tom Karkinsky and Nadine Riedel, Corporate Taxation and the Choice of Patent Location within Multinational Firms, December 2009

2880 Kai A. Konrad, Florian Morath and Wieland Müller, Taxation and Market Power, December 2009

2881 Marko Koethenbuerger and Michael Stimmelmayr, Corporate Taxation and Corporate Governance, December 2009

2882 Gebhard Kirchgässner, The Lost Popularity Function: Are Unemployment and Inflation no longer Relevant for the Behaviour of Germany Voters?, December 2009

2883 Marianna Belloc and Ugo Pagano, Politics-Business Interaction Paths, December 2009

2884 Wolfgang Buchholz, Richard Cornes and Dirk Rübbelke, Existence and Warr Neutrality for Matching Equilibria in a Public Good Economy: An Aggregative Game Approach, December 2009

2885 Charles A.E. Goodhart, Carolina Osorio and Dimitrios P. Tsomocos, Analysis of Monetary Policy and Financial Stability: A New Paradigm, December 2009

2886 Thomas Aronsson and Erkki Koskela, Outsourcing, Public Input Provision and Policy Cooperation, December 2009

2887 Andreas Ortmann, "The Way in which an Experiment is Conducted is Unbelievably Important": On the Experimentation Practices of Economists and Psychologists, December 2009

2888 Andreas Irmen, Population Aging and the Direction of Technical Change, December 2009

2889 Wolf-Heimo Grieben and Fuat Şener, Labor Unions, Globalization, and Mercantilism, December 2009

2890 Conny Wunsch, Optimal Use of Labor Market Policies: The Role of Job Search Assistance, December 2009 
2891 Claudia Buch, Cathérine Tahmee Koch and Michael Kötter, Margins of International Banking: Is there a Productivity Pecking Order in Banking, too?, December 2009

2892 Shafik Hebous and Alfons J. Weichenrieder, Debt Financing and Sharp Currency Depreciations: Wholly vs. Partially Owned Multinational Affiliates, December 2009

2893 Johannes Binswanger and Daniel Schunk, What is an Adequate Standard of Living during Retirement?, December 2009

2894 Armin Falk and James J. Heckman, Lab Experiments are a Major Source of Knowledge in the Social Sciences, December 2009

2895 Hartmut Egger and Daniel Etzel, The Impact of Trade on Employment, Welfare, and Income Distribution in Unionized General Oligopolistic Equilibrium, December 2009

2896 Julian Rauchdobler, Rupert Sausgruber and Jean-Robert Tyran, Voting on Thresholds for Public Goods: Experimental Evidence, December 2009

2897 Michael McBride and Stergios Skaperdas, Conflict, Settlement, and the Shadow of the Future, December 2009

2898 Ben J. Heijdra and Laurie S. M. Reijnders, Economic Growth and Longevity Risk with Adverse Selection, December 2009

2899 Johannes Becker, Taxation of Foreign Profits with Heterogeneous Multinational Firms, December 2009

2900 Douglas Gale and Piero Gottardi, Illiquidity and Under-Valuation of Firms, December 2009

2901 Donatella Gatti, Christophe Rault and Anne-Gaël Vaubourg, Unemployment and Finance: How do Financial and Labour Market Factors Interact?, December 2009

2902 Arno Riedl, Behavioral and Experimental Economics Can Inform Public Policy: Some Thoughts, December 2009

2903 Wilhelm K. Kohler and Marcel Smolka, Global Sourcing Decisions and Firm Productivity: Evidence from Spain, December 2009

2904 Marcel Gérard and Fernando M. M. Ruiz, Corporate Taxation and the Impact of Governance, Political and Economic Factors, December 2009

2905 Mikael Priks, The Effect of Surveillance Cameras on Crime: Evidence from the Stockholm Subway, December 2009

2906 Xavier Vives, Asset Auctions, Information, and Liquidity, January 2010

2907 Edwin van der Werf, Unilateral Climate Policy, Asymmetric Backstop Adoption, and Carbon Leakage in a Two-Region Hotelling Model, January 2010 
2908 Margarita Katsimi and Vassilis Sarantides, Do Elections Affect the Composition of Fiscal Policy?, January 2010

2909 Rolf Golombek, Mads Greaker and Michael Hoel, Climate Policy without Commitment, January 2010

2910 Sascha O. Becker and Ludger Woessmann, The Effect of Protestantism on Education before the Industrialization: Evidence from 1816 Prussia, January 2010

2911 Michael Berlemann, Marco Oestmann and Marcel Thum, Demographic Change and Bank Profitability. Empirical Evidence from German Savings Banks, January 2010

2912 Øystein Foros, Hans Jarle Kind and Greg Shaffer, Mergers and Partial Ownership, January 2010

2913 Sean Holly, M. Hashem Pesaran and Takashi Yamagata, Spatial and Temporal Diffusion of House Prices in the UK, January 2010

2914 Christian Keuschnigg and Evelyn Ribi, Profit Taxation and Finance Constraints, January 2010

2915 Hendrik Vrijburg and Ruud A. de Mooij, Enhanced Cooperation in an Asymmetric Model of Tax Competition, January 2010

2916 Volker Meier and Martin Werding, Ageing and the Welfare State: Securing Sustainability, January 2010

2917 Thushyanthan Baskaran and Zohal Hessami, Globalization, Redistribution, and the Composition of Public Education Expenditures, January 2010

2918 Angel de la Fuente, Testing, not Modelling, the Impact of Cohesion Support: A Theoretical Framework and some Preliminary Results for the Spanish Regions, January 2010

2919 Bruno S. Frey and Paolo Pamini, World Heritage: Where Are We? An Empirical Analysis, January 2010

2920 Susanne Ek and Bertil Holmlund, Family Job Search, Wage Bargaining, and Optimal Unemployment Insurance, January 2010

2921 Mariagiovanna Baccara, Allan Collard-Wexler, Leonardo Felli and Leeat Yariv, Gender and Racial Biases: Evidence from Child Adoption, January 2010

2922 Kurt R. Brekke, Roberto Cellini, Luigi Siciliani and Odd Rune Straume, Competition and Quality in Regulated Markets with Sluggish Demand, January 2010

2923 Stefan Bauernschuster, Oliver Falck and Niels Große, Can Competition Spoil Reciprocity? - A Laboratory Experiment, January 2010 
2924 Jerome L. Stein, A Critique of the Literature on the US Financial Debt Crisis, January 2010

2925 Erkki Koskela and Jan König, Profit Sharing, Wage Formation and Flexible Outsourcing under Labor Market Imperfection, January 2010

2926 Gabriella Legrenzi and Costas Milas, Spend-and-Tax Adjustments and the Sustainability of the Government's Intertemporal Budget Constraint, January 2010

2927 Piero Gottardi, Jean Marc Tallon and Paolo Ghirardato, Flexible Contracts, January 2010

2928 Gebhard Kirchgässner and Jürgen Wolters, The Role of Monetary Aggregates in the Policy Analysis of the Swiss National Bank, January 2010

2929 J. Trent Alexander, Michael Davern and Betsey Stevenson, Inaccurate Age and Sex Data in the Census PUMS Files: Evidence and Implications, January 2010

2930 Stefan Krasa and Mattias K. Polborn, Competition between Specialized Candidates, January 2010

2931 Yin-Wong Cheung and Xingwang Qian, Capital Flight: China's Experience, January 2010

2932 Thomas Hemmelgarn and Gaetan Nicodeme, The 2008 Financial Crisis and Taxation Policy, January 2010

2933 Marco Faravelli, Oliver Kirchkamp and Helmut Rainer, Social Welfare versus Inequality Concerns in an Incomplete Contract Experiment, January 2010

2934 Mohamed El Hedi Arouri and Christophe Rault, Oil Prices and Stock Markets: What Drives what in the Gulf Corporation Council Countries?, January 2010

2935 Wolfgang Lechthaler, Christian Merkl and Dennis J. Snower, Monetary Persistence and the Labor Market: A New Perspective, January 2010

2936 Klaus Abberger and Wolfgang Nierhaus, Markov-Switching and the Ifo Business Climate: The Ifo Business Cycle Traffic Lights, January 2010

2937 Mark Armstrong and Steffen Huck, Behavioral Economics as Applied to Firms: A Primer, February 2010

2938 Guglielmo Maria Caporale and Alessandro Girardi, Price Formation on the EuroMTS Platform, February 2010

2939 Hans Gersbach, Democratic Provision of Divisible Public Goods, February 2010 